\title{
A REVIEW ON MEDICINAL PROPERTIES OF CENTELLA ASIATICA
}

\author{
VED PRAKASH ${ }^{1 *}$, NISHITA JAISWAL ${ }^{2}$, MRINAL SRIVASTAVA ${ }^{2}$
}

${ }^{1}$ Department of Biotechnology, Motilal Nehru National Institute of Technology, Allahabad, Uttar Pradesh, India. ${ }^{2}$ Department of Biotechnology, CET IILM AHL, Greater Noida, Uttar Pradesh, India. Email: Ved.mits@gmail.com

Received: 16 June 2017, Revised and Accepted: 23 August 2017

ABSTRACT

Plant-based drug discovery has drawn the attention of researchers, especially the one used as traditional medicines. Centella asiatica is traditional Ayurveda medicine widely used in India and across Asia for treating a variety of diseases. The aerial parts and roots are used for medicinal purpose, and its chemical constituents have wide therapeutic applications in areas of antimicrobial, anti-inflammatory, anticancer, neuroprotective, antioxidant, and wound healing activities. Many of its uses have been proven scientifically, and bioactive ingredients have been validated. In this review, we have done a critical evaluation of available literature looking for the pharmacological importance of $C$. asiatica. Further studies will be helpful to discover more bioactive compounds their exact mode of actions

Keywords: Centella asiatica, Pharmacology, Chemical constituents, Therapeutic usage.

(C) 2017 The Authors. Published by Innovare Academic Sciences Pvt Ltd. This is an open access article under the CC BY license (http://creativecommons. org/licenses/by/4. 0/) DOI: http://dx.doi.org/10.22159/ajpcr.2017.v10i10.20760

\section{INTRODUCTION}

The plant is commonly known as Gotu Kola, Asiatic pennywort, Indian pennywort or Spadeleaf and belongs to Umbelliferae/Apiaceae family. In China, Southeast Asia, India, Sri Lanka, Oceania, and Africa, the plant has long been used as vegetable. In Southeast Asia, it is traditionally used for the treatment of a wide variety of disorders such as skin diseases, rheumatism, inflammation, syphilis, mental illness, epilepsy, hysteria, dehydration, and diarrhea [1,2]. Centella asiatica (Gotu Kola) is used in Indian systems of medicine for enhancing memory and for the treatment of skin diseases and nervine disorders [3]. The plant medicinal properties have long been utilized by the people of Java and Indonesia. In China, it is indigenously called as Gotu kola, and over 2000 years ago, it was one of the documented "miracle elixirs of life" [4]. Herbal medicines can be used as adaptogens, these plant derived drugs either reduce stress reactions in the alarm phase and provide a certain degree of safety against long-term stress [5]. C. asiatica (Umbelliferae) syn. Hydrocotyle asiatica is used to treat various ailments across India which includes body aches, headaches, insanity, asthma, leprosy, ulcers, eczemas, and wound healing [6]. To find out new potential compounds for therapeutic use, screening of medicinal plant is vital [7].

The plant has significantly drawn the attention of scientific groups in the recent years as it has multiple usages in the treatment of ailments. In Fig. 1, major pharmacological usage in the treatment of ailments has been outlined followed by its detailed description.

\section{CHEMICAL CONSTITUENTS}

The plant has long been used as folklore medicine for the treatment of a variety of diseases. Chemically been identified leading to therapeutic properties. Asiatic acid, asiaticoside, and madecassoside form the major constituents responsible for pharmacological value apart from being rich in flavonoids and terpenoids [8]. Centelloid was term given for different constituents of secondary metabolites produced by plant which mainly comprised of pentacyclic triterpenoid saponins [9]. P-cymene-(44\%) along with other volatile compounds was found to be in a prominent amount in the essential oil of $C$. asiatica on analysis with gas chromatography-mass spectrometry (GC-MS) [10]. Centellin, asiatic, and centellicin were isolated from the aerial part of the plant, and further, their structures had been determined using 2D nuclear magnetic resonance technique [11]. From plant extract using high-performance liquid chromatography to identify bioactive compounds, madecassoside, asiaticoside, madecassic acid, and asiatic acid were found in the significant amount [12]. A quantitative estimation of triterpenoids showed highest asiaticoside content $(6.42 \%)$ in leaf samples collected in Mangoro region [13]. New triterpene and a saponin, $2 \alpha, 3 \beta, 23$-trihydroxyurs-20-en-28-oic acid and $2 \alpha, 3 \beta, 23$ trihydroxyurs-20-en-28-oic acid 0- $\alpha$-l-rhamnopyranosy-(1 $\rightarrow 4)-0-\beta$-dglucopyranosyl $(1 \rightarrow 6)-0-\beta$-d glucopyranosyl ester, have been isolated from the aerial part of $C$. asiatica, and their structures were determined using spectral methods [14].

\section{ANTICANCER ACTIVITY}

On A549 and PC9/G lung cancer, cell line inhibitory concentration 50 $\left(\mathrm{IC}_{50}\right)$ values of $\mathrm{A}-3$ were $26.03 \pm 2.47$ and $25.57 \pm 0.51$, respectively, due to the presence of asiatic acid as major component [15]. Against the cell lines of human breast cancer (MDA MB-231), mouse melanoma (B16F1), and rat glioma (C6), the aqueous extract of $C$. asiatica had shown inhibitory activity with IC50 values of $698.0,648.0$, and $1000.0 \mu \mathrm{g} / \mathrm{mL}$, respectively [16]. The methanolic extract of $\mathrm{C}$. asiatica (Linn) showed inhibitory effect on MCF-7 cell lines, and induced apoptosis in MCF7 cells as indicated by nuclear condensation, increased annexin staining, loss of mitochondrial membrane potential, and induction of DNA breaks was identified by TUNEL reactivity [17]. The effect of $C$. asiatica juice was checked on human HepG2 cell line using MTT assay, and it showed cytotoxic effects on tumor cells in a dose-dependent manner. At a concentration above $0.1 \%$ of juice, a higher amount of DNA damage and apoptotic cell death was observed on human HepG2 cell line [18].

Asiatic acid was evaluated for antiproliferative effect in lung cancer cells using MTT assay. Oral administration of AA inhibited weight and tumor volume significantly in lung cancer xenograft model [19]. In another study, asiatic acid showed induced apoptosis and decreased viability in human melanoma SK-MEL-2 cells in a dose-dependent manner [20]. Asiatic acid derived from $C$. asiatica showed antiproliferative effects on RPMI 8226 cells. It decreased the expression levels of focal adhesion kinase (FAK), and the probable mechanism of AA may be related to the inhibition of signal transduction mediated by FAK [21]. Asiatic acid, asiaticoside, and madecassic acid was the major composition of titrated extract of $C$. asiatica, and asiaticoside reduces melanogenesis in B16F10 mouse melanoma by checking tyrosinase mRNA expression [22]. In long- 


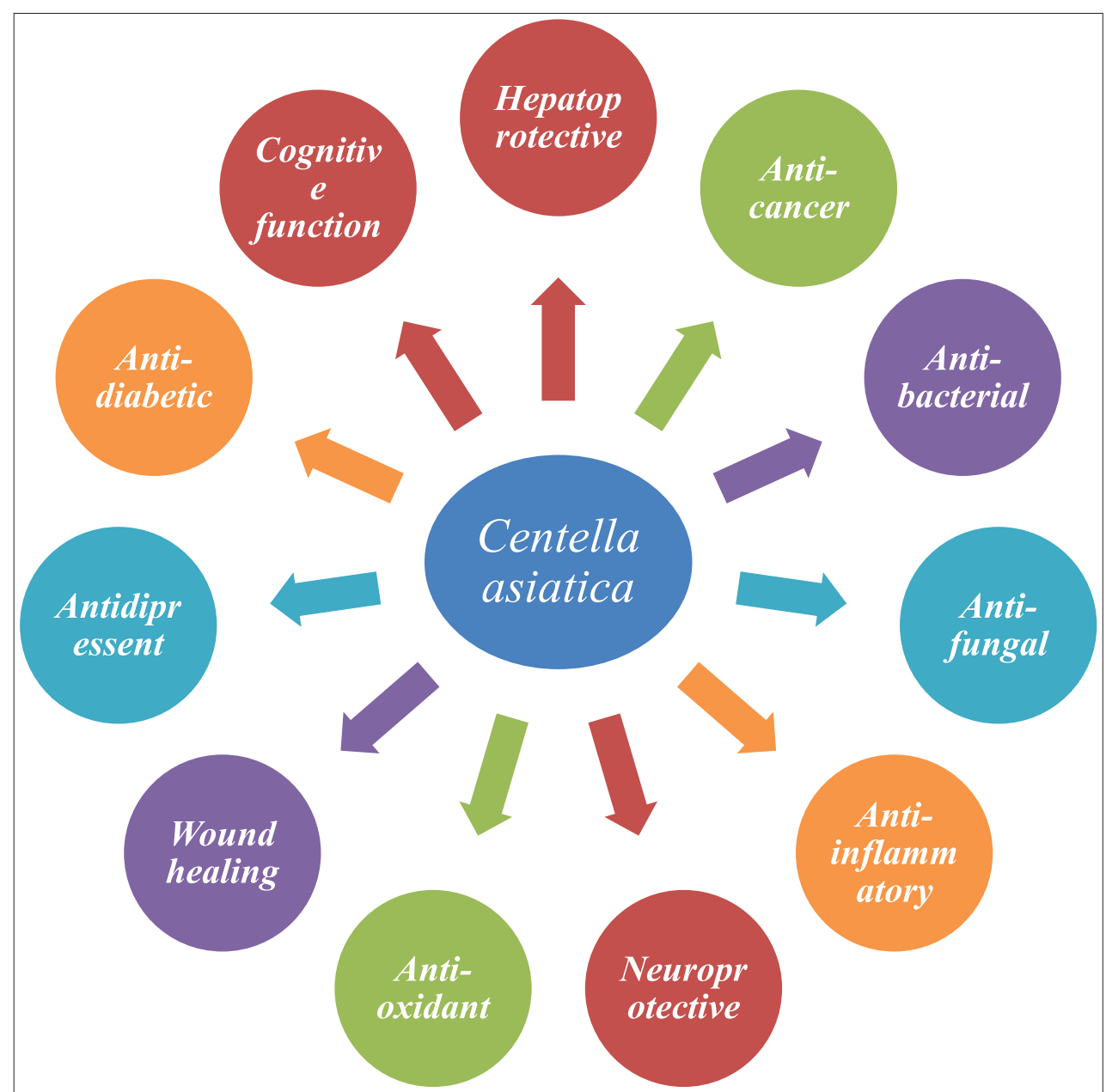

Fig. 1: Pharmacological activities of Centella asiatica

term culture at a concentration of $8 \mathrm{ug} / \mathrm{ml}$, partially purified fractions inhibited the growth of mouse lung fibroblast (L-929) cells [23]. Reduction up to $50 \%$ in viability was observed in ovarian cancer cells treated with $40 \mathrm{ug} / \mathrm{ml}$ concentration of asiatic acid, and it also showed cell cycle arrest at the G0/G1 phase and increased apoptosis by 7-10 folds [24]. Induction of apoptosis was observed in A-549 cell line due to presence of asiatic acid which helped in regulation of miR-1290, BCL2 protein level, and cell cycle regulation [25].

\section{ANTIBACTERIAL ACTIVITY}

Methanol hot extract from $C$. asiatica leaves was taken to check the antibacterial activity which was assessed by zone of inhibitionand minimum inhibitory concentration (MIC) value ( $2 \mu \mathrm{g} /$ disc) by disc diffusion method. In vitro antibacterial activity of the plant extract against Staphylococcus aureus ATCC 25923 and methicillin resistance S. aureus (wild type) showed a zone of inhibition of $5 \mathrm{~mm}$ and $7 \mathrm{~mm}$ respectively [26]. In a study, it was observed that essential oil extract showed antibacterial properties against Gram-positive (Bacillus subtilis and S. aureus) and Gram-negative (Escherichia coli, Pseudomonas aeruginosa, and Shigella sonnei) with MIC values ranging from 1.25 to $0.039 \mathrm{mg} / \mathrm{ml}$ [27]. Bacillus cereus and Listeria monocytogenes $10403 \mathrm{~S}$ were selected to study the antibacterial activity in C. asiatica under both normal and osmatic stress condition. At 95\% ethanolic extract, antibacterial activity was enhanced twice under osmotic stress condition. The MIC of $C$. asiatica was observed to be $16 \mu \mathrm{l} / \mathrm{ml}$ against B. cereus while $8 \mu \mathrm{l} / \mathrm{ml}$ for L. monocytogenes $10403 \mathrm{~S}$ [28]. MS media was used to culture leaf explants, and its antibacterial activity against B. cereus, E. coli, S. aureus, and P. aeruginosa was evaluated; methanol extracts of leaf and callus displayed maximum inhibitory effect against the tested organisms [29].

\section{ANTIFUNGAL ACTIVITY}

The petroleum ether, ethanol, chloroform, $\mathrm{n}$-hexane, and aqueous extract of $C$. asiatica showed activity against Aspergillus niger and C. albicans with a zone of inhibition of $14,16,13,13$, and $11 \mathrm{~mm}$ and $13,15,15,11$, and $9 \mathrm{~mm}$, respectively. The control Ketoconazole $(10 \mu \mathrm{g})$ showed the inhibition of $12 \mathrm{~mm}$ [30]. Ethanolic extract of C. asiatica was checked for antifungal activity against Aspergillus flavus, and Penicillium citrinum exhibited the strongest antimold activity (percentage mycelial inhibition $=26.3 \mathrm{~mm}$ ) [31]. $100 \%$ ethanolic extract of $C$. asiatica showed a zone of inhibition of $15.4 \mathrm{~mm}$ against A. niger [32]. Following agar well diffusion method, antimicrobial activity was checked for ethanolic extract of plant against $A$. niger and Candida albicans, an inhibition of 16 and $15 \mathrm{~mm}$ was observed, respectively, while control ketoconazole $(10 \mu \mathrm{g})$ gave a inhibition zone of 12 and $10 \mathrm{~mm}$ [30]. Against Candida albicans, on an average $5 \mathrm{~mm}$, zone of inhibition was observed while the standard miconazole nitrate showed an inhibition of $20 \mathrm{~mm}$ [33].

\section{ANTI-INFLAMMATORY ACTIVITY}

Anti-inflammation is widely used methodology in experimental oncology which helps to examine the inflammation defensive potential of natural products (betulinic acid, $\alpha$-amyrin acetate, lupeol acetate, oleanolic acid, and ursolic acid) and synthetic entities [34]. Terpenoid is major constituents among of secondary metabolites secreted by plants. It helps to cope up stress condition and supports defense activities. Plants with medicinal properties are rich in these compounds such as ceramide and different forms of terpenoids [35]. Pentacyclic triterpenoid and saponins are collectively known as centelloids. Among different constituents, triterpenoid saponins were mainly 
expected to be responsible for therapeutic actions [9]. Hypotonicityinduced human red blood cell membrane breakdown was inhibited by $C$. asiatica. At different concentrations, membrane stabilization was observed for diclofenac sodium and methanolic extracts, and at a dose of $2000 \mu \mathrm{g} / \mathrm{ml}$, maximum membrane stabilization of $C$. asiatica extracts was noticed to be $94.97 \%$ [36]. At concentration of $2 \mathrm{mg} / \mathrm{kg}$, the CA extract showed moderate anti-inflammatory property on prostaglandin E2-induced inflammation in a dose-dependent manner [37]. In another study, the aqueous and alcoholic extract of $C$. asiatica showed $46.31 \%$ and $71.18 \%$, respectively, inhibition of edema after $3 \mathrm{hrs}$, while the standard ibuprofen showed an inhibition of $66.66 \%$ [38]. At the $4^{\text {th }}$ and $5^{\text {th }}$ hrs, after $\lambda$-carrageenan (Carr) supplementation, the asiatic acid reduced paw edema by regulation of catalase, superoxide dismutase (SOD), and glutathione in the liver tissue [39]. In another study, measurement of paw size was taken before carrageenan injection and then $1,2,3$, and $4 \mathrm{hrs}$ after carrageenan injection. It was observed that the methanolic extract showed significant inhibition was the highest at $3 \mathrm{hrs}$ at $200 \mathrm{mg} / \mathrm{kg}$ dose which was slightly lower than indomethacin effect [40].

\section{NEUROPROTECTIVE ACTIVITY}

Neuroprotection aspect of C. asiatica mainly involves enzyme inhibition, prevention of amyloid plaque formation in Alzheimer's disease, dopamine neurotoxicity in Parkinson's disease, and reducing oxidative stress [41]. Water extract of $C$. asiatica was evaluated on the activity of subtypes of phospholipase A2 (PLA2) in primary cultures of rat cortical neurons, asiaticoside present in extract inhibited cPLA2 and sPLA2 activities [42]. In male Sprague-Dawley rats, improved learning and memory were observed on acute administration of asiatic acid [43]. Neuroprotective potential of modern medicine constituents of the plant includes asiatic acid, madecassic acid, and brahmaside as well as flavonoids madecassoside and madesiatic acid [44]. C. asiatica was explored for neuroprotective effect on cell death and cognitive irregulation in aluminum-treated rat. Significant improvement in memory performance, oxidative defense was observed on chronic administration of CA [45]. The plant is known to utilize neuroprotective effects by attenuating the changes in an animal model such as pathological neurobehavioral and neurochemical properties. Phosphoinositides-assisted cytodynamics and synaptic function show the neuroprotective effects of asiaticoside in the rat which includes mode of ROT-infused hemiparkinsonism [46].

\section{ANTIOXIDANT PROPERTY}

Free radical and reactive oxygen species (ROS) are the main reason behind aging. All organisms have a mechanism to deal with such reactive groups, free radical scavengers provide protection to the organism. The plant extract obtained from Turkey and India was compared with a standardized extract of plant obtained from China. The three extract at concentration of $250,500,1000$, and $2000 \mu \mathrm{g} / \mathrm{mL}$ showed radical scavenging activity for 2,2-diphenyl-1-picrylhydrazyl (DPPH) assay: CA-STD $>$ CA-TR $>$ CA-IND [47]. C. asiatica extract and powder was evaluated for reduction in oxidative stress in Sprague-Dawley rats. Results showed a decrease in the generation of ROS and oxidative stress in the rats. It was also noted that there was a significant decrease in SOD level [48]. Essential oil of $C$. asiatica extracted through steam distillation showed to be excellent antioxidant for food containing lipids. Its activity was quite comparable with the synthetic antioxidant butylhydroxyanisole (BHA) [49]. Polyphenol, flavonoid, $\beta$-carotene, tannin, Vitamin C, and DPPH compounds are readily found in C. asiatica contributing to significantly higher antioxidant activity in the herb [50]. Crude methanolic extract on continuous supplementation for 14 days resulted in increase in level of antioxidant enzymes and ascorbic acid level reduced in lymphoma-bearing mice [51]. Extracts of $C$. asiatica in different solvents such as chloroform, hexane, acetone, ethyl acetate, methanol, and water were assessed for antioxidant potential. The DPPH and hydroxyl radical scavenging activity were tested for methanolic extract which showed the $\mathrm{IC}_{50}$ value of $0.07 \mathrm{mg} / \mathrm{ml}$ and $500 \mu \mathrm{g} / \mathrm{ml}$, respectively [52].

\section{WOUND HEALING}

An increase in DNA, protein, and collagen content of granulation tissues was observed on supplementation of extract of C. asiatica resulting in collagen synthesis and cellular proliferation at wound site [53]. The extract of $C$. asiatica considerably enhanced the wound breach power in incision model when compared to controls $(\mathrm{p}<0.001)$, wound contraction rate was noticeably enhanced as compared to control wounds $(\mathrm{p}<0.001)$, and wounds epithelized faster when treated with an extract of CA [54]. Rats treated with extract showed a better tensile strength of wound after 7 days of wound infliction when compared with control [55]. A study on ethanol-induced gastric lesion oral administration of CE $(0.05,0.25$, and $0.50 \mathrm{~g} / \mathrm{kg})$ before ethanol administration considerably lowered mucosal myeloperoxidase activity checked gastric lesions formation ( $58 \%$ to $82 \%$ reduction) and in a dose-dependent manner [56]. Fibroblast division and collagen synthesis were enhanced in wound on treatment with extract of C. asiatica [57].

\section{ANTIDEPRESSANT}

Compared to diazepam C. asiatica possesses antianxiety effect but has no effect on behavioral despair [58]. Total triterpenes and imipramine from $C$. asiatica were evaluated for antidepressant activity using forced swimming test, the result showed a reduction in stillness duration and regulated amino acid levels [59]. In another study, decrease in corticosterone level in serum and enhanced 5-HT, NE, DA and their metabolites 5-HIAA and MHPG in rat brain were observed [60]. Standardized extract showed a reversal of physiological and behavioral changes following OBX-induced depression in rats [61]. Forced swim test was performed in male Sprague-Dawley rat treated with asiatic acid and midazolam+asiatic acid, significant result was observed in the ration of open-arm time, maximum speed, and time spent in the AA group and the midazolam+AA group $(\mathrm{p}<0.05)$ [62].

\section{ANTIDIABETIC ACTIVITY}

Antidiabetic properties of leaves extract of $C$. asiatica was evaluated in alloxan-induced rat by administering extract at a concentration of 250 , 500 , and $1000 \mathrm{mg} / \mathrm{kg}$ after $3 \mathrm{hrs}$ of ingestion reduction in blood glucose level was noticed by $32.6 \%, 38.8 \%$, and $29.9 \%$, respectively [63]. Effect of ethanol extract was tested in streptozotocin $(50 \mathrm{mg} / \mathrm{kg})$-induced Wistar rats. Studying the serum glucose, urea cholesterol, lipid, liver glycogen level, and body weight, the antidiabetic activity of extract at concentration of $200 \mathrm{mg} / \mathrm{kg}$ was noticed [64]. In a study, lower inhibitory activities of $\alpha$-amylase of C. asiatica extract and rutin were observed when compared to acarbose and an anti-diabetic drug [65]. Extract of C. asiatica led to reducing blood glucose level in dosedependent manner by $29.4 \%, 32.8 \%, 33.6 \%$, and $35.7 \%$, respectively, at doses of 50,100, 200, and $400 \mathrm{mg}$ per kg body weight [66]. In alloxaninduced rats, reduction in blood glucose level was observed at a dose level of $50 \mathrm{mg} / \mathrm{kg}$ bwt of $C$. asiatica juice [67]. The effect of intestinal disaccharides and alpha amylase was inhibited, and lowered glucose absorption was observed when supplemented with plant extract [68]. Long-term administration of plant extract reversed the blood glucose level to normal in obese diabetic rat [69]. Asiatic acid was found to reduce blood glucose level in Goto-Kakizaki (GK) rat by enhancing fibrosis of islets in diabetes which plays a vital role in the prevention of islets dysfunction [70]. In diabetic Wistar rat model, asiatic acid showed to preserve and restore beta cell mass [71].

\section{COGNITIVE FUNCTION}

Asiatic acid was found to prevent spatial working memory and reduction of neurogenesis defects in the hippocampal region caused by 5 -FU chemotherapy [72]. Water extract of $C$. asiatica was observed to enhance synaptic differentiation and dendritic arborization with reference to $A \beta$ which causes cognitive improvement [73]. In a study, gotu-kola extract was supplemented for weeks in defined concentration results showed to be effective in the treatment of cognitive function impairment after stroke [74]. Asiatic acid has potential to restore the 
impairment of cell proliferation, spatial working memory caused by treatment with valproic acid [75]. Water extract helped to improve cognitive function by activation of antioxidant response gene and mitochondrial biogenesis [76], normalized calcium homeostasis [77]. In another study, asiatic acid was found to enhance hippocampal neurogenesis which can serve as potent cognitive enhancer [78]. Asiaticoside isolated from Hydrocotyle sibthorpioides helps in scavenging free radical enhancing activity of antioxidant enzymes, improving synaptic plasticity, reducing the level of $A \beta$, and reversing abrupt changes in AchE activity [79]. In cognitive-related disorders, mitochondrial dysfunction and oxidative stress have major role, in a study carried out aluminum-induced cognitive dysfunction and mitooxidative damage $C$. asiatica have proved to carry neuroprotective potential [45]. The study was done in primary culture of rat cortical neurons to check the activity of subtypes of PLA2, asiaticoside present in extract inhibited cPLA2 and SPLA2 activities [42]. On experiment conducted on mice model oral supplementation of asiatic acid $(100 \mathrm{mg} / \mathrm{kg})$, significant improvement in cognitive function was observed in the Morris maze test and retained glutathione and lipid peroxidation and SOD activity in cortex and hippocampus to control levels [80]. In another study, C. asiatica proved to have a protective role against D-glucose-induced biochemical, behavioral, and mitochondrial dysfunction in mice [81]. Acute administration of asiatic acid was studied on male Sprague-Dawley rats for memory and learning, treatment at $30 \mathrm{mg} / \mathrm{kg}$ of asiatic acid significantly improved memory [43]. The healing effect of $C$. asiatica was observed against colchicine-induced cognitive impairment [82] and lead acetate-induced changes in oxidative biomarkers in the central nervous system [83]. Cyclic AMP response element binding protein phosphorylation level was enhanced in primary culture of rat embryonic cortical cells on treatment with plant extract, thus improving memory function [84]. In another finding, it was found that high dose of plant extract-enhanced memory and increased N100 constituent amplitude of event-related potential [85]. In an intracerebroventricular streptozotocin model of Alzheimer's disease in rat plant, aqueous extract was found effective in combating the cognitive deficit and oxidative stress [86].

\section{HEPATOPROTECTIVE}

Effect of methanolic extract of CA was evaluated in Type 2 diabetes mellitus, hepatic concentrations of interleukin-1 $\beta$, MCP-1, and tumor necrosis factor alpha in diabetic control rats orally treated with deionized water, group were reduced to $68 \%, 75 \%$, and $63 \%$ of normal control rats orally treated with deionized water values, respectively [87]. In dimethylnitrosamine-induced liver injury C. asiatica noticeably enhanced fibrosis of liver tissues by mass periportal \pm bridging necrosis, intralobular degeneration, and focal necrosis [88]. On INH-treated albino rats, CA $(100 \mathrm{mg} / \mathrm{kg} \mathrm{bw})$ dose was found effective to improve liver histology [89]. In cyclophosphamide (CYP)-induced hepatotoxicity in rats, Centella asiatica triterpene saponins saponins regulated hepatic function by restoring cytokine production [90]. Hepatoprotective activity of plant extract was checked against Ccl4-induced liver injury, and the extract showed hepatoprotective activity most probably due to the presence of asiaticoside (14.5\%) in the extract [91]. The functional group of asiatic acid was modified at C2, C3, C23, and C28. Compound 9 showed hepatoprotective effects against GaIN-induced hepatotoxicity $(66.4 \%$ protection at $50 \mu \mathrm{M})$ and moderate hepatoprotective activities against CCl4-induced hepatotoxicity (20.7\% protection at $50 \mu \mathrm{M})$ [92]. Asiatic acid protects liver injury by onset of Smad7-dependent inhibition of TGF-beta/Smad-assisted fibrogenesis [93]. Conventionally, used plants to get rid of liver dysfunction might, therefore, could be potential source for new hepatoprotective compounds for development as pharmaceutical entities [94].

\section{CONCLUSION}

C. asiatica is potential herb with an array of health-care applications. It is widely accepted that plant has got neuroprotective activities and helpful in brain improvement. Plants have proved to bear low toxicity and higher efficacy in clinical treatment with prominent activities such as anticancer, antibacterial, antifungal, anti-inflammation, neuroprotection, antioxidant, wound healing, and antidepressant as mentioned in above manuscript. As C. asiatica is an endangered species using plant tissue culture mass propagation major can be helpful, and callus and suspension culture techniques can be harnessed for secondary metabolite extraction. Germplasm conservation could be a possible way to preserve this precious plant. More studies are required to characterize and establish the chemical compounds responsible for a wide range of therapeutic activity. Due to the presence of wide bioactive compound, the plant has vast application. The plant can be a safer alternative for the formulation of new drugs. Further research is needed to confirm their activities mentioned in ancient scripts followed by clinical studies for their safe application for humans.

\section{REFERENCES}

1. Shanghai PR. Jiangsu new medical college. Dictionary of Chinese Materia Medica. China: Shanghai Scientific and Technical Publishing House; 1977. p. 1874.

2. Yu QL, Duan HQ, Takaishi Y, Gao WY. A novel triterpene from Centella asiatica. Molecules 2006;11(9):661-5.

3. Jamil SS, Nizami Q, Salam M. Centella asiatica (Linn.) Urban-a review. Nat Prod Radiance 2007;6(2):158-70.

4. Diwan PV, Karwande I, Singh AK. Anti-anxiety profile of manduk parni (Centella asiatica) in animals. Fitoterapia 1991;62:253-7.

5. Wagner $H$, Nörr H, Winterhoff $H$. Plant adaptogens. Phytomedicine 1994;1(1):63-76

6. Mishra LC, editor. Scientific Basis for Ayurvedic Therapies. New York: CRC Press; 2003.

7. Periyasamy A, Mahalingam K. Phytochemical screening and antimicrobial activity from five Indian medicinal plants against human pathogens. Middle East J Sci Res 2010;5(6):477-82.

8. Roy DC, Barman SK, Shaik MM. Current updates on Centella asiatica: Phytochemistry, pharmacology and traditional uses. Med Plant Res 2013;3(4):70-7.

9. James JT, Dubery IA. Pentacyclic triterpenoids from the medicinal herb, Centella asiatica (L.) Urban. Molecules 2009;14(10):3922-41.

10. Francis SC, Thomas MT. Essential oil profiling of Centella asiatica (L.) Urb-a medicinally important herb. South Indian J Biol Sci 2016;2(1):16973.

11. Siddiqui BS, Aslam H, Ali ST, Khan S, Begum S. Chemical constituents of Centella asiatica. J Asian Nat Prod Res 2007;9(3-5):407-14.

12. Inamdar PK, Yeole RD, Ghogare AB, De Souza NJ. Determination of biologically active constituents in Centella asiatica. J Chromatogr A 1996;742(1-2):127-30

13. Randriamampionona D, Diallo B, Rakotoniriana F, Rabemanantso C, Cheuk K, Corbisier AM, et al. Comparative analysis of active constituents in Centella asiatica samples from Madagascar: Application for ex situ conservation and clonal propagation. Fitoterapia 2007;78(78):482-9.

14. Yu QL, Duan HQ, Gao WY, Takaishi Y. A new triterpene and a saponin from Centella asiatica. Chin Chem Lett 2007;18(1):62-4.

15. Wang L, Xu J, Zhao C, Zhao L, Feng B. Antiproliferative, cellcycle dysregulation effects of novel asiatic acid derivatives on human non-small cell lung cancer cells. Chem Pharm Bull (Tokyo) 2013;61(10):1015-23.

16. Pittella F, Dutra RC, Junior DD, Lopes MT, Barbosa NR. Antioxidant and cytotoxic activities of Centella asiatica (L) Urb. Int J Mol Sci 2009;10(10):3713-21.

17. Babykutty S, Padikkala J, Sathiadevan P, Vijayakurup V, Azis T, Srinivas P, et al. Apoptosis induction of Centella asiatica on human breast cancer cells. Afr J Tradit Complement Altern Med 2009;6(1):9-16.

18. Hussin F, Eshkoor SA, Rahmat A, Othman F, Akim A. The centella asiatica juice effects on DNA damage, apoptosis and gene expression in hepatocellular carcinoma (HCC). BMC Complement Altern Med 2014;14:32.

19. Wu T, Geng J, Guo W, Gao J, Zhu X. Asiatic acid inhibits lung cancer cell growth in vitro and in vivo by destroying mitochondria. Acta Pharm Sin B 2017;7(1):65-72.

20. Park BC, Bosire KO, Lee ES, Lee YS, Kim JA. Asiatic acid induces apoptosis in SK-MEL-2 human melanoma cells. Cancer Lett 2005;218(1):81-90.

21. Zhang J, Ai L, Lv T, Jiang X, Liu F. Asiatic acid, a triterpene, inhibits cell proliferation through regulating the expression of focal adhesion 
kinase in multiple myeloma cells. Oncol Lett 2013;6(6):1762-6.

22. Kwon KJ, Bae S, Kim K, An IS, Ahn KJ, An S, et al. Asiaticoside, a component of Centella asiatica, inhibits melanogenesis in B16F10 mouse melanoma. Mol Med Rep 2014;10(1):503-7.

23. Babu TD, Kuttan G, Padikkala J. Cytotoxic and anti-tumour properties of certain taxa of Umbelliferae with special reference to Centella asiatica (L.) Urban. J Ethnopharmacol 1995;48(1):53-7.

24. Ren L, Cao QX, Zhai FR, Yang SQ, Zhang HX. Asiatic acid exerts anticancer potential in human ovarian cancer cells via suppression of PI3K/Akt/mTOR signalling. Pharm Biol 2016;54(11):2377-82.

25. Kim KB, Kim K, Bae S, Choi Y, Cha HJ, Kim SY, et al. MicroRNA-1290 promotes asiatic acid-induced apoptosis by decreasing BCL2 protein level in A549 non-small cell lung carcinoma cells. Oncol Rep 2014;32(3):1029-36

26. Zaidan MR, Noor Rain A, Badrul AR, Adlin A, Norazah A, Zakiah I. In vitro screening of five local medicinal plants for antibacterial activity using disc diffusion method. Trop Biomed 2005;22(2):165-70.

27. Oyedeji OA, Afolayan AJ. Chemical composition and antibacterial activity of the essential oil of Centella asiatica. Growing in South Africa. Pharma Biol 2005:43(3):249-52.

28. Pitinidhipat N. Antibacterial activity of Chrysanthemum indicum, Centella asiatica and Andrographis paniculata against Bacillus cereus and Listeria monocytogenes under osmotic stress. AUJT 2015;15(4):239-45.

29. Sekar T, Ayyanar M, Pillai YJ. Phytochemical screening and antibacterial activity of leaf and callus extracts of Centella asiatica. Bangladesh J Pharmacol 2011;6(1):55-60.

30. Dash BK, Faruquee HM, Biswas SK, Alam MK, Sisir SM, Prodhan UK. Antibacterial and antifungal activities of several extracts of Centella asiatica L. against some human pathogenic microbes. Life Sci Med Res 2011;2011:1-5.

31. Dhiman R, Aggarwal N, Aneja KR, Kaur M. In vitro antimicrobial activity of spices and medicinal herbs against selected microbes associated with juices. Int J Microbiol 2016;2016:9015802.

32. Idris NA, Nadzir MM. Antimicrobial activity of Centella asiatica on Aspergillus niger and Bacillus subtilis. Chem Eng Trans 2017;56:1381-6.

33. Sultan RA, Mahmood SB, Azhar I, Ahmed SW, Mahmood ZA. Biological activities assessment of Centella asiatica (Linn.). J Herbs Spices Med Plants 2014;20(3):319-27.

34. Sultana N, Saify ZS. Naturally occurring and synthetic agents as potential anti-inflammatory and immunomodulants. Antiinflamm Antiallergy Agents Med Chem 2012;11(1):3-19.

35. Prakash V. Terpenoids as source of anti-inflammatory compounds. Asian J Pharm Clin Res 2017;10(3):68-76.

36. Chippada SC, Volluri SS, Bammidi SR, Vangalapati M. In vitro anti-inflammatory activity of methanolic extract of Centella asiatica by HRBC membrane stabilisation. Rasayan J Chem 2011;4(2):457-60.

37. Somchit MN, Sulaiman MR, Zuraini A, Samsuddin L, Somchit N, Israf DA, et al. Antinociceptive and antiinflammatory effects of Centella asiatica. Indian J Pharmacol 2004;36(6):377.

38. George M, Joseph L, Ramaswamy. Anti-allergic, anti-pruritic, and anti-inflammatory activities of Centella asiatica extracts. Afr J Tradit Complement Altern Med 2009;6(4):554-9.

39. Huang SS, Chiu CS, Chen HJ, Hou WC, Sheu MJ, Lin Y, et al. Antinociceptive activities and the mechanisms of anti-inflammation of asiatic acid in mice. Evid Based Complement Alternat Med 2011:2011:895857.

40. Saha S, Guria T, Singha T, Maity TK. Evaluation of analgesic and antiinflammatory activity of chloroform and methanol extracts of Centella asiatica Linn. ISRN Pharmacol 2013;2013:789613.

41. Orhan IE. Centella asiatica (L.) Urban: From traditional medicine to modern medicine with neuroprotective potential. Evid Based Complement Altern Med 2012;2012:946259.

42. Defillipo PP, Raposo AH, Fedoce AG, Ferreira AS, Polonini HC, Gattaz WF, et al. Inhibition of cPLA2 and sPLA2 activities in primary cultures of rat cortical neurons by Centella asiatica water extract. Nat Prod Commun 2012;7(7):841-3.

43. Nasir MN, Habsah M, Zamzuri I, Rammes G, Hasnan J, Abdullah J. Effects of asiatic acid on passive and active avoidance task in male Spraque - Dawley rats. J Ethnopharmacol 2011;134(2):203-9.

44. Thomas TN, Thomas PM. Patent Application No. 14/848,372. U.S; 2015.

45. Prakash A, Kumar A. Mitoprotective effect of Centella asiatica against aluminum-induced neurotoxicity in rats: Possible relevance to its antioxidant and anti-apoptosis mechanism. Neurol Sci 2013;34(8):1403-9.

46. Gopi M, Arambakkam Janardhanam V. Asiaticoside: Attenuation of rotenone induced oxidative burden in a rat model of hemiparkinsonism by maintaining the phosphoinositide-mediated synaptic integrity. Pharmacol Biochem Behav 2017;155:1-15.

47. Orhan IE, Atasu E, Senol FS, Ozturk N, Demirci B, Das K, et al. Comparative studies on Turkish and Indian Centella asiatica (L.) Urban (gotu kola) samples for their enzyme inhibitory and antioxidant effects and phytochemical characterization. Ind Crops Prod 2013;47:316-322.

48. Hussin M, Abdul-Hamid A, Mohamad S, Saari N, Ismail M, Bejo MH. Protective effect of Centella asiatica extract and powder on oxidative stress in rats. Food Chem 2007;100(2):535-41.

49. Raza SA, Adnan A, Qureshi F. Comparison of antioxidant activity of essential oil of Centella asiatica and Butylatedhydroxyanisole in sunflower oil at ambient conditions. Biharean Biol 2009;3(1):71-5.

50. Chandrika UG, Kumara PA. Gotu Kola (Centella asiatica): Nutritional properties and plausible health benefits. Adv Food Nutr Res 2015;76:125-57.

51. Jayashree G, Kurup Muraleedhara GK, Sudarslal S, Jacob VB. Antioxidant activity of Centella asiatica on lymphoma-bearing mice. Fitoterapia 2003;74(5):431-4.

52. Anand T, Mahadeva N, Phani KG, Farhath K. Antioxidant and DNA damage preventive properties of Centella asiatica (L) Urb. Pharm J 2010;2(17):53-8

53. Suguna L, Sivakumar P, Chandrakasan G. Effects of Centella asiatica extract on dermal wound healing in rats. Indian J Exp Biol 1996;34(12):1208-11.

54. Shetty BS, Udupa SL, Udupa AL, Somayaji SN. Effect of Centella asiatica L (Umbelliferae) on normal and dexamethasone-suppressed wound healing in Wistar Albino rats. Int $\mathrm{J}$ Low Extrem Wounds 2006;5(3):137-43.

55. Somboonwong J, Kankaisre M, Tantisira B, Tantisira MH. Wound healing activities of different extracts of Centella asiatica in incision and burn wound models: An experimental animal study. BMC Complement Altern Med 2012;12:103.

56. Cheng CL, Koo MW. Effects of Centella asiatica on ethanol induced gastric mucosal lesions in rats. Life Sci 2000;67(21):2647-53.

57. Yao CH, Yeh JY, Chen YS, Li MH, Huang CH. Wound-healing effect of electrospun gelatin nanofibres containing Centella asiatica extract in a rat model. J Tissue Eng Regen Med 2017;11(3):905-15.

58. Bhavna D, Jyoti K. Centella asiatica: The elixir of life. Int J Res Ayurveda Pharm 2011;2(2):431-8.

59. Chen Y, Han T, Qin L, Rui Y, Zheng H. Effect of total triterpenes from Centella asiatica on the depression behavior and concentration of amino acid in forced swimming mice. Zhong Yao Cai 2003;26(12):870-3.

60. Chen Y, Han T, Rui Y, Yin M, Qin L, Zheng H. Effects of total triterpenes of Centella asiatica on the corticosterone levels in serum and contents of monoamine in depression rat brain. Zhon Yao Cai 2005;28(6):492-6.

61. Kalshetty P, Aswar U, Bodhankar S, Sinnathambi A, Mohan V, Thakurdesai P. Antidepressant effects of standardized extract of Centella asiatica $\mathrm{L}$ in olfactory bulbectomy model. Biomed Aging Pathol 2012;2(2):48-53.

62. Ceremuga TE, Valdivieso D, Kenner C, Lucia A, Lathrop K, Stailey O, Taylor A. Evaluation of the anxiolytic and antidepressant effects of asiatic acid, a compound from Gotu kola or Centella asiatica, in the male Sprague Dawley rat. AANA J 2015;83(2):91-8.

63. Rahman MM, Sayeed MS, Haque MA, Hassan MM, Islam SA. Phytochemical screening, antioxidant, anti-Alzheimer and antidiabetic activities of Centella asiatica. J Nat Prod Plant Resour 2012;2(4):504-11

64. Gayathri V, Lekshmi P, Padmanabhan RN. Anti-diabetes activity of ethanol extract of Centella asiatica (L.) urban (whole plant) in Streptozotocin-induced diabetic rats, isolation of an active fraction and toxicity evaluation of the extract. Int $\mathrm{J}$ Med Aromat Plants 2011;1(3):278-6

65. Supkamonseni N, Thinkratok A, Meksuriyen D, Srisawat R. Hypolipidemic and hypoglycemic effects of Centella asiatica (L.) extract in vitro and in vivo. Indian J Exp Biol 2014;52(10):965-71.

66. Haque S, Naznine T, Ali M, Azad TT, Morshed T, Afsana NA, et al. Antihyperglycemic activities of leaves of Brassica oleracea, Centella asiatica and Zizyphus mauritiana: Evaluation through oral glucose tolerance tests. Adv Nat Appl Sci 2013;7(5):519-26.

67. Rahman S, Jamal MM, Parvin A, Mahfuz-Al-Mamun M, Islam MR. Antidiabetic activity of Centella asiatica (L.) urbana in alloxan induced Type 1 diabetic model rats. J Biosci 2012;19:23-7.

68. Kabir AU, Samad MB, D'Costa NM, Akhter F, Ahmed A, Hannan JM. Anti-hyperglycemic activity of Centella asiatica is partly mediated by carbohydrase inhibition and glucose-fiber binding. BMC Complement Altern Med 2014:14:31. 
69. Maulidiani, Abas F, Khatib A, Perumal V, Suppaiah V, Ismail A, et al. Metabolic alteration in obese diabetes rats upon treatment with Centella asiatica extract. J Ethnopharmacol 2016;180:60-9.

70. Wang X, Lu Q, Yu DS, Chen YP, Shang J, Zhang LY, et al. Asiatic acid mitigates hyperglycemia and reduces islet fibrosis in Goto-Kakizaki rat, a spontaneous Type 2 diabetic animal model. Chin J Nat Med 2015;13(7):529-34.

71. Liu J, He T, Lu Q, Shang J, Sun H, Zhang L. Asiatic acid preserves beta cell mass and mitigates hyperglycemia in streptozocin-induced diabetic rats. Diabetes Metab Res Rev 2010;26(6):448-54.

72. Chaisawang P, Sirichoat A, Chaijaroonkhanarak W, Pannangrong W, Sripanidkulchai B, Wigmore $\mathrm{P}$, et al. Asiatic acid protects against cognitive deficits and reductions in cell proliferation and survival in the rat hippocampus caused by 5 -fluorouracil chemotherapy. PLoS One 2017;12(7):e0180650.

73. Gray NE, Zweig JA, Murchison C, Caruso M, Matthews DG, Kawamoto $\mathrm{C}$, et al. Centella asiatica attenuates Aß-induced neurodegenerative spine loss and dendritic simplification. Neurosci Lett 2017;646:24-9.

74. Farhana KM, Malueka RG, Wibowo S, Gofir A. Effectiveness of Gotu Kola extract 750 ?mg and 1000 ?mg compared with folic acid 3 ?mg in improving vascular cognitive impairment after stroke. Evid Based Complement Alternat Med 2016;2016:2795915.

75. Umka Welbat J, Sirichoat A, Chaijaroonkhanarak W, Prachaney P, Pannangrong W, Pakdeechote P, et al. Asiatic acid prevents the deleterious effects of valproic acid on cognition and hippocampal cell proliferation and survival. Nutrients 2016;8(5). pii: E303.

76. Gray NE, Harris CJ, Quinn JF, Soumyanath A. Centella asiatica modulates antioxidant and mitochondrial pathways and improves cognitive function in mice. J Ethnopharmacol 2016;180:78-6.

77. Gray NE, Sampath H, Zweig JA, Quinn JF, Soumyanath A. Centella asiatica attenuates amyloid- $\beta$-induced oxidative stress and mitochondrial dysfunction. J Alzheimers Dis 2015;45(3):933-46.

78. Sirichoat A, Chaijaroonkhanarak W, Prachaney P, Pannangrong W, Leksomboon R, Chaichun A, et al. Effects of asiatic Acid on spatial working memory and cell proliferation in the adult rat hippocampus. Nutrients 2015;7:8413-23.

79. Lin X, Huang R, Zhang S, Wei L, Zhuo L, Wu X, et al. Beneficial effects of asiaticoside on cognitive deficits in senescence-accelerated mice. Fitoterapia 2013;87(10):69-77.

80. Xu MF, Xiong YY, Liu JK, Qian JJ, Zhu L, Gao J. Asiatic acid, a pentacyclic triterpene in Centella asiatica, attenuates glutamateinduced cognitive deficits in mice and apoptosis in SH-SY5Y cells. Acta Pharmacol Sin 2012;33(5):578-7.

81. Kumar A, Prakash A, Dogra S. Centella asiatica attenuates D-galactoseinduced cognitive impairment, oxidative and mitochondrial dysfunction in mice. Int J Alzheimers Dis 2011;2011:347569.

82. Kumar A, Dogra S, Prakash A. Neuroprotective effects of Centella asiatica against intracerebroventricular colchicine-induced cognitive impairment and oxidative stress. Int J Alzheimers Dis 2009;2009. pii: 972178

83. Ponnusamy K, Mohan M, Nagaraja HS. Protective antioxidant effect of Centella asiatica bioflavonoids on lead acetate induced neurotoxicity. Med J Malaysia 2008;63 Suppl A:102.

84. Xu Y, Cao Z, Khan I, Luo Y. Gotu Kola (Centella asiatica) extract enhances phosphorylation of cyclic AMP response element binding protein in neuroblastoma cells expressing amyloid beta peptide. J Alzheimers Dis 2008;13(3):341-9.

85. Wattanathorn J, Mator L, Muchimapura S, Tongun T, Pasuriwong O, Piyawatkul N, et al. Positive modulation of cognition and mood in the healthy elderly volunteer following the administration of Centella asiatica. J Ethnopharmacol 2008;116(2):325-2.

86. Veerendra Kumar MH, Gupta YK. Effect of Centella asiatica on cognition and oxidative stress in an intracerebroventricular streptozotocin model of Alzheimer's disease in rats. Clin Exp Pharmacol Physiol 2003;30(5-6):336-42.

87. Oyenihi AB, Chegou NN, Oguntibeju OO, Masola B. Centella asiatica enhances hepatic antioxidant status and regulates hepatic inflammatory cytokines in Type 2 diabetic rats. Pharm Biol 2017;55(1):1671-8.

88. Choi MJ, Zheng HM, Kim JM, Lee KW, Park YH, Lee DH. Protective effects of Centella asiatica leaf extract on dimethylnitrosamine-induced liver injury in rats. Mol Med Rep 2016;14(5):4521-8.

89. Ghosh K, Indra N, Jagadeesan G. The ameliorating effect of Centella asiatica ethanolic extract on albino rats treated with isoniazid. J Basic Clin Physiol Pharmacol 2017;28(1):67-7.

90. Duggina P, Kalla CM, Varikasuvu SR, Bukke S, Tartte V. Protective effect of centella triterpene saponins against cyclophosphamideinduced immune and hepatic system dysfunction in rats: Its possible mechanisms of action. J Physiol Biochem 2015;71(3):435-4.

91. Antony B, Santhakumari G, Merina B, Sheeba V, Mukkadan J. Hepatoprotective effect of Centella asiatica (L) in carbon tetrachlorideinduced liver injury in rats. Indian J Pharm Sci 2006;68(6):772.

92. Jeong BS, Kim YC, Lee ES. Modification of C2, 3, 23, 28 functional groups on asiatic acid and evaluation of hepatoprotective effects. Bull Korean Chem Soc 2007;28(6):977-82.

93. Tang LX, He RH, Yang G, Tan JJ, Zhou L, Meng XM, et al. Asiatic acid inhibits liver fibrosis by blocking TGF-beta/Smad signaling in vivo and in vitro. PLoS One 2012;7(2):e31350.

94. Rajalingam D, Varadharajan R, Palani S. Evaluation of hepatoprotective and antioxidant effect of Combretum albidum $\mathrm{G}$. don against $\mathrm{CCl} 4$ induced hepatotoxicity in rats. Int J Pharm Pharm Sci 2016;8(9):218-23. 